\title{
Yozgat ilinde yaşayan kadınların kullandığı kontraseptif yöntemler
}

\section{Contraceptive methods used by women living in Yozgat City}

\section{Emel Kıyak Çağlayan*, Mustafa Kara, Nilden Aslan}

Kadın Hastalıkları ve Doğum Anabilim Dalı (Yrd. Doç. Dr. E. K. Çağlayan, Doç. Dr. M. Kara), Bozok Üniversitesi Tıp Fakültesi, TR-66200 Yozgat, Halk Sağlığı Anabilim Dalı (Dr. N. Aslan), Ondokuz Mayıs Üniversitesi Tıp Fakültesi, TR-55139 Samsun

\section{Özet}

Amaç. Bu çalışmanın amacı Yozgat il merkezinde yaşayan kadınların aile planlaması hakkındaki bilgi düzeylerini ve kullanılan doğum kontrol yöntemlerini belirlemektir. Yöntemler. Çalışma Ekim 2010-Temmuz 2011 tarihleri arasında Kadın Hastalıkları ve Doğum Polikliniğine başvuranlar arasından çalışmaya katılmayı kabul eden 441 hastaya anket yöntemi uygulanarak yapıldı. Anket formları hemşire tarafından karşılıklı görüşme ile dolduruldu. Bulgular. Çalışmaya

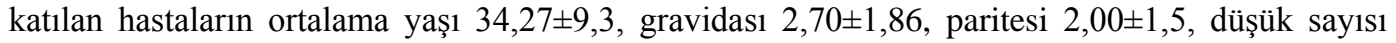
$0,30 \pm 1,2$ ve yaşayan çocuk sayısı 2,05 $\pm 1,25$ olarak bulundu. Hastaların \%72,4'ü kontraseptif yöntem kullanmaktaydı. En sık kullanılan kontraseptif yöntem \%41 ile Rahim İçi Araç (RİA) olarak saptandı. İkinci ve üçüncü en sık kullanılan yöntemler sırasıyla geri çekme (\% 23) ve kondom $(\% 19,5)$ idi. Yöntem kullanmayanların oranı \%27,6 idi ve bunun en sık sebebi olarak $\% 17,7$ ile çocuk sahibi olma isteği gelmekteydi. Sonuç. Çalışmamızda herhangi bir aile planlaması yöntemi kullanma oranı \% 72,4 olup, en fazla tercih edilen yöntem RİA'dır. Çalışmaya katılanlar arasında aile planlaması konusundaki bilgi sahibi olma düzeyi \%88,2 bulunmuştur.

Anahtar sözcükler: Aile planlaması, bilgi düzeyi, doğum kontrol yöntemi

\begin{abstract}
Aim. The aim of this study was to detect the knowledge levels and and type of contraceptive methods in women living in the center of Yozgat, a central Anatolian city. Methods. This study was done in 441 women who agreed to participate into the study attending Obstetrics and Gynecology Service between October 2010 and July 2011 by using a questionnaire application. The inquiries were filled out by a nurse with face to face conversation. Results. Of the 441 women in the study group, demographic parameters was as the following: the average age $34.27 \pm 9.3$ years, gravidity $2.70 \pm 1.86$, parity $2.00 \pm 1.5$, abortion $0.30 \pm 1.2$, and number of live children $2.05 \pm 1.25$. The rates of contraceptive method usage were $72.4 \%$. The most common used contraceptive method was detected to be intrauterine device $(41 \%)$. The second and third most common used methods were withdrawal $(23 \%)$ and condom $(19.5 \%)$, respectively. The percentage of the women who did not use any contraceptive method was $27.6 \%$ and the most common cause of this condition was child expectancy $(63.9 \%)$. Conclusion. In our study, the rate of any family planning method usage is $72.4 \%$ and IUD is the most preferred method. Among the participants of the study, the level of knowledge about family planning is $88.2 \%$.
\end{abstract}

Keywords: Family planning, knowledge level, contraception method

Geliş tarihi/Received: 5 Haziran 2013; Kabul tarihi/Accepted: 20 Ocak 2014

*İletişim adresi:

Dr. Emel Kıyak Çağlayan, Kadın Hastalıkları ve Doğum Anabilim Dalı, Bozok Üniversitesi Tıp Fakültasi, TR-66200 Yozgat. E-posta: emelkiyak@ hotmail.com 


\section{Giriş}

Aile planlaması, kişilerin istedikleri zaman istedikleri sayıda çocuğa sahip olmalarını konu alan hizmetler bütünüdür. Bireylerin aile planlaması hizmetlerinden yeterli düzeyde faydalanabilmesi son derece önemlidir. Bunun sonucu olarak hem istenmeyen gebelikler hem de aşırı doğurganlık önlenerek anne-çocuk sağlığ1 ve bunun yanı sıra toplum sağglığ1 da olumlu etkilenecek, ülke kaynaklarının etkin kullanımı gerçekleşecektir [1]. Ülkemizde yaklaşık 30 yıldır bu konuda uygulanan politikalar neticesinde önemli gelişmeler olmasına rağmen günümüzde aile planlaması yöntemlerinin kullanımı halen arzu edilen düzeylerde değildir [2-4]. Ülkemizde sık kullanılan modern aile planlaması yöntemleri sırası ile RİA, kondom ve doğum kontrol haplarıdır. Doğal aile planlaması yöntemleri arasında geri çekme, takvim yöntemi, emzirme ve diğer yöntemler (servikal mukus yöntemi, servikal palpasyon yöntemi, takvim yöntemi) yer alır. Ülkemizde son yıllarda modern yöntemler ile ilgili bilgi düzeyinin artması ile bu yöntemlerin kullanım oranları da artış göstermektedir [1, 4]. Çalışmamızda Yozgat ili merkezinde aile planlaması yöntem kullanım sıklığı ve bu konudaki bilgi düzeyini değerlendirmeyi amaçladık.

\section{Gereç ve yöntem}

Kadın Hastalıkları ve Doğum polikliniğine Ekim 2010-Temmuz 2011 tarihleri arasında başvuran 15-49 yaş arasındaki hastalardan görüşmeyi kabul eden 441 kadın ile bu konuda eğitilmiş anketör hemşire tarafindan yüz yüze görüşme yapıldı. Hastalara aile planlaması yöntemi kullanıp kullanmadıkları, kullanıyorlar ise hangisi olduğu, yöntemden memnuniyetsizlikleri, yöntem kullanmıyorlarsa bunun sebepleri, aile planlaması ile bilgilere nasıl ulaştıkları ve aile planlaması eğitimlerinin toplum için önemini içeren sorular soruldu.

Verilerin analizi SPSS 15 programı kullanılarak değerlendirildi. Değerler ortalama \pm standart sapma, sayı ve yüzde olarak ifade edildi.

\section{Bulgular}

Çalışmaya katılan hastaların ortalama yaşı $34,27 \pm 9,3$, ortalama gravidası $2,70 \pm 1,86$, ortalama paritesi $2,00 \pm 1,5$, ortalama abort sayıs $0,30 \pm 1,2$, ortalama yaşayan çocuk sayıs1 $2,05 \pm 1,25 \mathrm{idi}$. İstenmeyen gebelik oran $\% 7,2$, ortalama evlenme yaş1 $19,73 \pm 3,68$, ortalama evlilik süresi $14,17 \pm 9,5$ idi. Hastaların \%89,3'ü kentte oturmaktaydı. Eğitim seviyesi açısından bakıldığında hastaların \%50,3'ü ilkokul mezunu, \%13,4'ü yüksekokul mezunu, \%9,3'ü okuryazar değildi. Hastaların \%72,4'i kontraseptif yöntem kullanmaktaydı. En sık kullanılan kontraseptif yöntem \%41 ile RİA olarak saptand1. \%23 ile geri çekilme ikinci sıklıkta, \%19,5 ile kondom 3. sırada yer almaktayd1. Cerrahi sterilizasyon $\% 7,5$, oral kontraseptif \%7,2, lavaj \%1,2, enjektabl yöntemler $\% 0,6$ siklıkta kullanılmaktaydı (Tablo 1).

Tablo 1. Hastaların tercih ettiği aile planlaması yöntemleri.

\begin{tabular}{lll}
\hline Kontraseptif yöntem & $\mathbf{n}$ & $\mathbf{\%}$ \\
\hline RİA & 181 & 41 \\
OKS & 32 & 7,2 \\
Kondom & 86 & 19,5 \\
Enjektabl & 3 & 0,6 \\
Cerrahi sterilizasyon & 33 & 7,5 \\
Lavaj & 5 & 1,2 \\
Geri çekme & 101 & 23 \\
\hline
\end{tabular}

Kadınların aile planlaması konusunda en sık bilgi aldıkları kişi hemşireler iken $(\% 53,3)$ doktordan bilgi alanlar ikinci sıradaydı (\%10,9). Hastaların \%11,8'i daha önceden hiçbir şekilde aile planlaması bilgisi almamışlar, \%14,9'u ise birden fazla kişiden bilgi aldıklarını ifade etmişlerdir (Tablo 2). Yöntem kullanmayanların oranı \%27,6 olup en sık 
yöntem kullanmama nedeni \%63,9 ile çocuk sahibi olma isteği gelmektedir. Hastaların \%19,6'sı bilgi eksikliği nedeniyle, \%7'si eşinin istememesi nedeniyle, \%5,5'de kanama komplikasyonu nedeniyle herhangi bir yöntem kullanmadıklarını belirtmişlerdir. Hayatları boyunca her hangi bir kontraseptif metod kullanmayanların oranı \%13,4'dür (Tablo 3).

Tablo 2. Hastaların bilgi aldığı kaynaklar.

\begin{tabular}{lll}
\hline Bilgi aldığı kişi & n & \% \\
\hline Doktor & 48 & 10,9 \\
Ebe - Hemşire & 235 & 53,3 \\
Eş & 25 & 5,7 \\
Arkadaş & 15 & 3,4 \\
Birden fazla kişi & 66 & 14,9 \\
Hiç bilgisi yok & 52 & 11,8 \\
\hline
\end{tabular}

Tablo 3. Hastaların yöntem kullanmama sebepleri.

\begin{tabular}{lll}
\hline Nedenler & n & \% \\
\hline Çocuk isteği & 282 & 63,9 \\
Yöntem kullanımı konusunda bilgi eksikliği & 86 & 19,6 \\
Eşinin istememesi & 31 & 7 \\
Kanama yapması & 24 & 5,5 \\
Eşinin yanında olmaması & 18 & 4 \\
\hline
\end{tabular}

Hastaların aile planlaması yöntemlerinin güvenilirliği konusundaki inanışları değerlendirildiğinde, \%40,1'i hiçbir kontraseptif yöntemi güvenli bulmaz iken \%31,7'si RİA, \%10 kondom, \%9,3 ile oral kontraseptifi güvenli bulmaktadır. Hastaların \%95,2'si aile planlaması hakkında bilgi sahibi olmanın ana-çocuk sağlığı ve aile bütçesine katkı sağladığını düşünmüşlerdir. İstenmeyen gebelik oranının en fazla görüldügü yöntem \%20 ile geri çekilme olarak saptanmıştır.

\section{Tartışma}

Dünyada her yıl yaklaşık 87 milyon planlanmayan gebelik oluşmakta ve bunların yaklaşık 40 milyonu doğum ile sonuçlanmaktadır. Planlı olmayan gebelikler anne ve çocuk sağlığını olumsuz etkilemektedir. Bunun yanında nüfus artışı ile birlikte ülke kaynaklarının kullanımı açısından ekonomik sıkıntıları da beraberinde getirmektedir [57]. Aile planlaması yöntemi kullanılmamasının başlıca sebepleri çocuk isteği, kişinin gebe olması, kısırlık yaptığı inanışı, lohusa olması, günah olması, kanser yaptığına dair inanışlar, eşin istememesi ve cinsel ilişkiye engel olması sayılabilmektedir [1]. Bizim çalışmamızda yöntem kullanılmamasının en sık sebepleri çocuk isteği, bilgi eksikliği, eşin istemesi, kanama yapması, eşinin yanında olmamasıdır. Çocuk isteği ve eşin yanında olmaması ile yöntem kullanımı doğal karşılanmaktadır. Ancak hastalarımızın önemli bir kısmı $(\% 19,6)$ bu yöntemler hakkında bilgi sahibi olmadıkları için korunmadıklarını ifade etmişlerdir ki, bu son derece önemlidir. Kişilerin kanama nedeniyle yöntem kullanmaması da aile planlaması hizmeti verilip yöntem kullanımı sağlandıktan sonra olası yöntem yan etkileri konusunda kişilerin izleminin devam edilmesinin gerekliliğini ortaya koymaktadır.

Çalışmamıza katılanlar arasında kontraseptif yöntem kullanma oranı \%72,4'tür. En yaygın kullanılan yöntem RİA olarak saptanmıştır (\%41). Bunu \%23 ile geri çekilme, \%19,5 ile kondom kullanımı izlemektedir. Yapılan bir çalışmada en sık kullanılan yöntem $\% 55$ ile RİA, \%40,7 ile geri çekme, \%39,8 ile kondom tespit edilmiş olup bizim çalışmamız ile benzer sonuç saptanmıştır [8]. Dünyada sterilizasyondan sonra en yaygın kullanılan ikinci yöntem RİA kullanımıdır [6]. Amerika'da tüm kadınlar içinde kontraseptif yöntemlerde ilk sırayı haplar $(\% 18,5)$ ikinci sira cerrahi sterilizasyon $(\% 16,6)$ üçüncü sırayı kondom $(\% 8,8)$ almaktadır ve RİA takılma oranı $\% 1,2$ dir. Sağlık personelinden bilgi alma seviyesi arttıkça RİA kullanımı artmaktadır. Çalışmamızda RİA 
takılması en yaygın kullanılan kontraseptif yöntem iken hastaların kendileri için en zararlı olarak gördügü yöntem yine RİA kullanımı olmuştur, bu durum da hastaların olumsuz düşüncelere sahip olmalarına rağmen bu yöntemden vazgeçmediklerini göstermektedir.

Geri çekme dünyada en yaygın kullanılan geçici kontraseptif yöntemlerden biridir [9]. Dünyada en yaygın kullanan ülkeler Romanya (\%35), Türkiye (\%27), Çek Cumhuriyeti'dir (\%24). Ülkemizde yapılan bir çalışmada da en yaygın kullanılan yöntem geri çekme olarak saptanmıştır [2, 7]. Bizim çalışmamızda geri çekme \%25,9 ile ikinci en sık kullanılan yöntem olarak bulunmuştur. Modern doğal aile planlaması yöntemi olarak kabul edilen servikal mukus değişiklikleri (bazal vücut 1sısı ile birlikte veya tek başına) ile fertil günlerin değerlendirilmesi yöntemi ise daha sık olarak gelişmiş ülkelerde kullanılmakta olup çalışmamızda bu yöntemi tercih eden hasta bulunmamaktadır [10]. Bunun nedeni çalışmamızdaki aile planlaması bilgisi alan kişilerin araç veya hormonal ajan kullanımı ile kendilerini daha güvende hissetmeleri olabilir.

Yeterli ve etkin hizmetlerin tüm bireylere ulaştırılması bireylerin yeterli ve etkin eğitimi ile gerçekleşmektedir. Yaptığımız çalışmada hastalarımızın \%11,8'inin daha önceden kontraseptif metod konusunda hiçbir bilgiye sahip olmadıklarını ifade etmişlerdir. Bu hastalar arasında en sık kullanılan yöntem geri çekilmedir. Hastaların eğitim ve bilgi düzeyleri arttıkça modern yöntemlerin kullanımının arttı̆̆ 1 görülmektedir. Çalışmaya katılan bireyler en fazla oranda sağlık personeli aracılığı ile bu bilgilere ulaştıklarını ifade etmişlerdir. $\mathrm{Bu}$ durum sağlı kuruluşlarına başvuru sırasında hastalarla yapılan görüşmeleri son derece önemli hale getirmektedir. Hastalarımızın eğitim düzeyi arttıkça doktor ve hemşireden bilgi sahibi olma oranları da artmaktadır. Yapılan çalışmalar da bu bulgumuzu desteklemektedir [2].

Aile planlamasının faydaları konusundaki genel düşünce ana çocuk sağlığına ve ülke ekonomisine olumlu katkı sağladığı yönündedir ki, bu yapılan eğitim ve hizmetlerin benimsenmesi konusunda önemlidir. Aile planlaması kullanımının yaygınlaşması bu konuda bilgili olma ile yakından ilişkilidir. Aile planlaması konusunda topluma verilecek eğitimlerin arttırılması bu bilinç düzeyinin yükseltilmesi için önemli bir faktör olacağı kesindir.

\section{Kaynaklar}

1. Özdemir İ, Yıldırım U, Demirci F, Duras G, Yücel O. Düzce'de yaşayan 15-49 yaş grubu Evli Kadınların Kontraseptif Yöntemi Kullanma ve Kullanmama Nedenleri. Düzce Tip Fakültesi Dergisi 2002; 4: 19-22.

2. Gılıç E, Ceyhan O, Özer A. Niğde Doğumevi'nde Doğum Yapan Kadınların Aile Planlaması Konusundaki Bilgi Tutum ve Davranışları. Fırat Tıp Dergisi 2009; 14: 237-41.

3. Pınar G, Öktem M, Algıer L, Doğan N, Zeyneloğlu H. Sağlık Personelinin Acil Kontrasepsiyona ilişkin bilgi görüş ve uygulamaları. J Turk Soc Obstet Gynecol 2005; 2: 204-9.

4. Aylaz R, Yekeler B, Çam HH, Güneş G. Ebelerin Doğal Aile Planlamas1 Yöntemlerine İlişkin Bilgi Tutum ve Davranışları. Fırat Sağlık Hizmetleri Dergisi 2009; 4: 151-8.

5. Şahin HG, Şahin HA, Zeteroğlu Ş, Kolusarı A. Van İli Yöresinde Aile Planlaması Yöntemleri Kullanmama Nedenleri. Turkiye Klinik J Gynecol Obst 2002; 12: 265-8.

6. Sağsöz N, Bayram M, Kamacı M. Kırıkkale ili ve Çevresinde Kullanılan Kontraseptif Yöntemler. Turkiye Klinikleri J Gynecol Obst 2000; 10: 266-9.

7. Karaçam Z, Önel K, Gerçek E. Effects of unplanned pregnancy on maternal health in Turkey. Midwifery 2011; 27: 288-93.

8. Bozkurt N, Özkan S, Onan A, Korucuoğlu U, Aygün R, Himmetoğlu O. Distribution of contraceptive use in a Turkish population. Eur J Obstet Gynecol Reprod Biol 2007; 131: 52-6. 
9. Yanıkerem E, Acar H, Elem E. Withdrawal users' perceptions of and experience with contraceptive methods in Manisa, Turkey. Midwifery 2006; 22: 274-84.

10. Mikolajczyk RT, Stanford JB, Rauchfuss M. Factors influencing the choice to use modern natural family planning. Contraception 2003; 67: 253-8. 